\title{
Avaliação do comportamento de ligação de montagem viga-pilar para estruturas de concreto pré-moldado
}

\author{
Analysis of behavior of beam-column assembly connection \\ for precast concrete structures
}

\section{Lisiane Pereira Prado Mounir Khalil El Debs}

\section{Resumo}

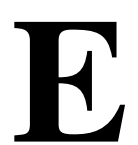

ste artigo apresenta a avaliação de uma ligação viga-pilar de estrutura de concreto pré-moldado para ser usada como ligação provisória durante a montagem. A ligação é constituída de perfil metálico de seção transversal em “U” embutido no pilar e um perfil metálico de seção transversal retangular vazada embutido na viga. Na montagem da estrutura, a ligação é realizada pelo encaixe dos elementos metálicos embutidos. Para avaliar o comportamento estrutural dos componentes da ligação, consolo e dente metálico, realizou-se um estudo com uma parte analítica e uma parte experimental. A parte experimental foi constituída de um pórtico estrutural, com a ligação em estudo, submetido a um carregamento estático e monotônico. Os principais resultados obtidos experimentalmente foram: a) o momento último para o consolo metálico referente ao momento fletor de plastificação da seção transversal foi 37,9\% maior que o valor determinado analiticamente e, em relação ao momento fletor de início de escoamento, o resultado obtido experimentalmente foi 15,8\% superior ao determinado analiticamente; e b) a resistência referente ao momento fletor de início de escoamento para o dente metálico foi $61,1 \%$ superior ao valor obtido analiticamente.

Palavras-chave: Concreto pré-moldado. Ligação viga-pilar. Dente metálico. Consolo metálico.

Lisiane Pereira Prado Universidade de São Paulo São Carlos - SP - Brasil

\section{Mounir Khalil El Debs Universidade de São Paulo São Carlos - SP - Brasil}

Recebido em 09/02/17 Aceito em 24/10/17

\begin{abstract}
The paper presents the evaluation of pinned connection between precast columns and beams, which can be used as temporary connections during the assembly phase. The use of a " $U$ " shaped steel corbel embedded in the column and a hollow rectamgular steel hanger embedded in the beam, was the proposed model for the connection. The connection between the beam and the column was accomplished by the fitting of elements. To evaluate the structural behavior of connections components, steel corbel and steel hanger, a both analytical and experimental study was conducted. The experimental part included a structural frame, with the temporary connection in study, which was submitted to a test with static and monotonic loadings. The main experimental results were: a) the last bending moment for the steel corbel, in relation to the bending moment of plastification of the cross section, was $37.9 \%$ higher than the analytically determined value and, in relation to the bending moment at the beginning of steel yielding, the result obtained experimentally was $15.8 \%$ higher than the one determined analytically; b) the strength related to the bending moment at the beginning of steel yielding, for the steel ranger, was $61.1 \%$ higher than that determined analytically.

Keywords: Precast concrete. Connection beam-column. Steel corbel. Steel hanger.
\end{abstract}




\section{Introdução}

No cenário atual da construção civil, as estruturas em concreto pré-moldado podem ser vistas com mais frequência nos canteiros de obras. Desde as edificações mais simples, como galpões comerciais e logísticos, até as mais complexas, acima de quatro pavimentos, é possível encontrar os principais elementos de concreto pré-moldado, como pilares, vigas e lajes. Esses elementos, que podem ser armados ou protendidos, são conectados entre si para formar as estruturas de concreto pré-moldado. $\mathrm{O}$ que diferencia o sistema construtivo convencional do sistema construtivo em prémoldado é a presença da ligação.

Nas estruturas de concreto pré-moldado, de modo geral, os pilares são engastados na fundação, e a ligação entre a viga e o pilar difere de acordo com a altura da estrutura. Para edifícios de pequena e média altura, as vigas são articuladas nos pilares, sendo esse tipo de ligação projetada de modo simplificado, não necessitando de detalhes complementares após a montagem dos elementos de concreto. No entanto, em edifícios com altura elevada, as vigas precisam ser ligadas rigidamente aos pilares. Nesse caso, a ligação tem maior complexidade de execução e, na maioria das vezes, é indispensável a finalização dela no local da obra mediante o uso de suportes provisórios.

A ligação entre os elementos de concreto prémoldado precisa ser concebida na fase inicial de projeto. A partir dessa definição é que será determinada a geometria dos elementos constituintes e, caso não seja executada do modo como foi projetada, poderá acarretar danos estruturais.

A sétima edição do Manual do Precast Concrete Institute (PCI) (PRECAST..., 2010) relata que o projeto de ligações é uma das considerações mais importantes no projeto estrutural das estruturas de concreto pré-moldado, sendo seu propósito transferir carga, restringir movimento e/ou promover estabilidade.

Os perfis metálicos como opção de ligação entre os elementos pré-moldados são empregados de diversas maneiras, de acordo com a solicitação do projeto. Armaduras adicionais soldadas nos elementos metálicos da ligação podem auxiliar na distribuição dos esforços. A finalização da ligação metálica por meio de soldas, parafusos ou apenas encaixe dos elementos é que vai diferenciar na distribuição dos esforços.

Oliveira Júnior (2012) analisou o comportamento da ligação rígida entre viga e pilar pré-moldado, solicitada por ações estáticas e dinâmicas, para casa de força de usina hidrelétrica. Essa ligação foi feita por meio do traspasse das barras da armadura longitudinal da viga com as barras passantes no pilar para garantir a continuidade dos momentos fletores positivo e negativo, preenchida com concreto reforçado com fibras de aço (Figura 1).

Diante do exposto, o presente artigo apresenta o comportamento de uma ligação provisória entre viga e pilar pré-moldado para ser usada como suporte na execução da ligação rígida proposta por Oliveira Junior (2012). Os elementos da ligação provisória consistem de um consolo metálico de perfil "U” introduzido no pilar, formado por chapas de aço soldadas (Figura 2a), que serve como apoio e travamento lateral para o dente metálico, embutido na viga pré-moldada, feito de chapas de aço soldadas, com seção retangular vazada (Figura 2b). O encaixe do dente no consolo metálico forma a ligação provisória (Figura 2c), que é articulada, pois não há barras de transmissão de esforços entre o pilar e a viga.

A fim de determinar a força resistente no consolo e dente metálico, construiu-se um pórtico estrutural com a ligação provisória em estudo, submetido a um carregamento monotônico. As dimensões dos elementos utilizados para a confecção do pórtico estrutural foram as mesmas estudadas por Oliveira Junior (2012), definida a partir do projeto estrutural da casa de força da Usina Hidrelétrica de Manso, utilizando uma escala de 1:3 para adaptar as condições de laboratório. Em uma extremidade do pórtico foi analisada a capacidade do consolo metálico, e para induzir sua ruptura o dente metálico apoiado sobre ele foi executado com espessura maior que a do consolo. Na outra extremidade do pórtico estrutural analisou-se a capacidade do dente metálico, que foi induzido a ruptura ao ser apoiado pelo consolo metálico com espessura superior àquele.

\section{Modelos analíticos}

\section{Consolo metálico}

Nos consolos de concreto, o arranjo das armaduras de aço ancoradas no concreto trabalha em conjunto com este para resistir aos esforços. $\mathrm{O}$ uso de perfis de aço como consolo pode ter a mesma resistência de um consolo de concreto, porém com a geometria reduzida em relação a este.

O PCI (PRECAST..., 2010) relata que existem muitas formas de utilizar o aço estrutural como: consolo metálico, como perfil duplo, tubos, placas e outros. Para seu dimensionamento é necessário recorrer a normas específicas de estruturas metálicas, como a NBR 8800 (ABNT, 2008), de 
onde foi obtida a simbologia para este artigo. A capacidade do concreto e das armaduras adicionais pode ser calculada de acordo com as considerações mostradas na Figura 3 e nas Equações (1) a (6) do manual do PCI (PRECAST..., 2010).

A resistência do concreto é calculada de acordo com a Equação (1).

$$
V_{c}=\frac{0,85 f_{c d} b l_{e}}{1+3,6 \frac{e}{l_{e}}}
$$

$V_{c}=$ força cortante resistida pelo concreto $(\mathrm{N})$;

$F_{c d}=$ resistência de cálculo à compressão do concreto (MPa);

$b$ = largura efetiva do bloco de compressão (mm);

$l_{e}=$ comprimento de embutimento (mm);

$a$ = distância do ponto de aplicação da força à face do pilar (mm); e

Onde:

Figura 1 - Esboço da ligação proposta por Oliveira J únior (2012)
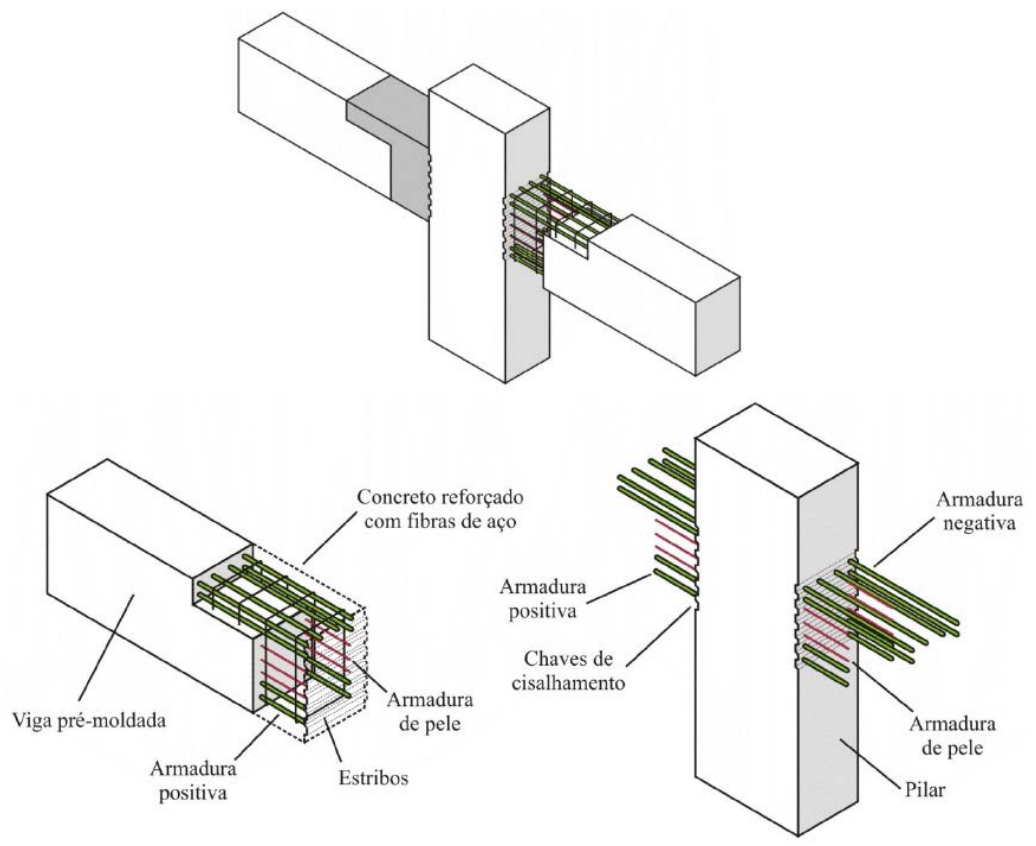

Figura 2 - Detalhe dos componentes e da ligação estudada

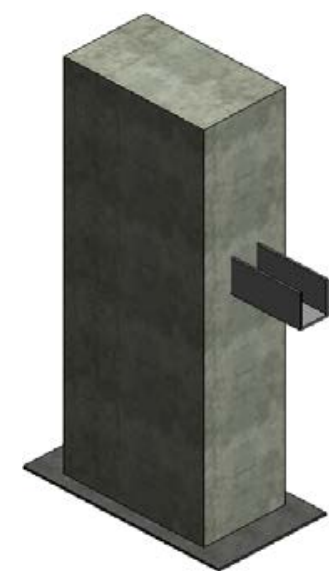

(a) Pilar pré-moldado com consolo metálico embutido

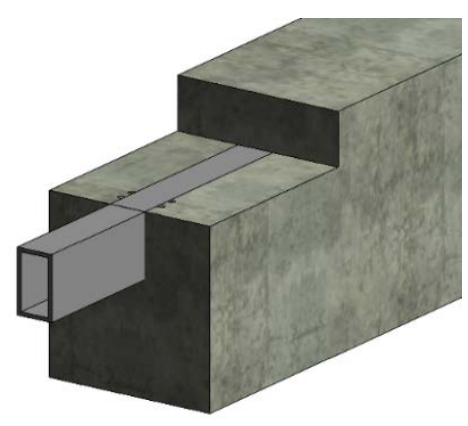

(b) Viga pré-moldado com dente metálico embutido

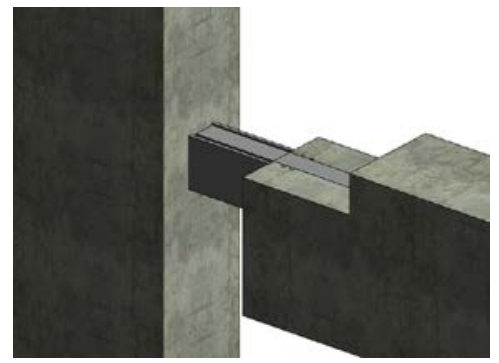

(c) Detalhe da ligação montada 
Figura 3 - Símbolos, nomenclaturas e variáveis do consolo metálico embutido
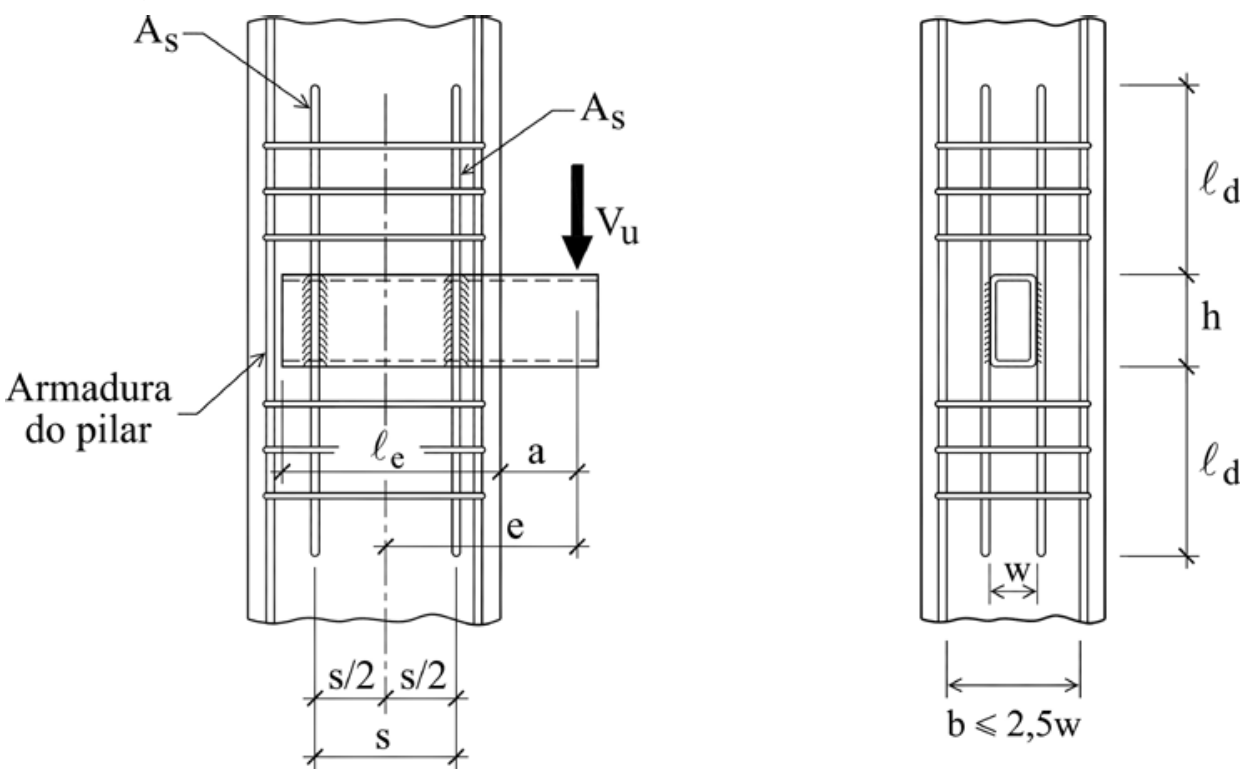

Fonte: adaptada de PCI (PRECAST..., 2010).

A contribuição adicional do reforço de aço soldado no perfil metálico pode ser escrita de acordo com a Equação (2).

$$
V_{r}=\frac{2 A_{s} f_{s d}}{1+\left(\frac{6 e}{4,8 s-l_{e}}\right)}
$$

Onde:

$V_{r}=$ força adicional resistida pelas armaduras de aço soldadas ao consolo metálico $(\mathrm{N})$;

$f_{s d}=$ resistência de cálculo ao escoamento do aço das armaduras $(\mathrm{N})$;

$A_{s}=$ área total das armaduras de aço soldadas ao consolo metálico $\left(\mathrm{mm}^{2}\right)$; e

$s=$ distância entre o centro das armaduras de aço soldadas no consolo metálico (mm).

De acordo com o manual do PCI (PRECAST..., 2010), se a soma das parcelas $V_{c}$ e $V_{r}$, em $\mathrm{kN}$, for maior que a força cortante aplicada no consolo, com seu valor de cálculo em $\mathrm{N}\left(V_{u}\right)$, o dimensionamento está seguro. Caso contrário, o dimensionamento não é aceitável.

$V_{d}=\left(V_{c}+V_{r}\right)$, com $V_{d} \geq V_{u}$

A resistência de cálculo a flexão (Equação 4) e ao cisalhamento (Equação 5) do consolo metálico pode ser determinada como:

$V_{n}=\frac{Z_{p} f_{y d}}{\alpha+\frac{0,5 V_{u}}{0,85 f_{c d} b}}$

$V_{n}=\left(0,6 f_{y d}\right) h t$

Eq. 5
Onde:

$V_{n}=$ resistência de cálculo à flexão do consolo metálico $(\mathrm{N})$;

$Z_{p}=$ módulo de resistência plástico do perfil de aço $\left(\mathrm{mm}^{3}\right)$;

$f_{y d}=$ resistência de cálculo ao escoamento da chapa de aço (MPa);

$V_{u}=$ força cortante aplicada no consolo com seu valor de cálculo $(\mathrm{N})$;

$b=$ distância entre as faces das armaduras longitudinais no pilar pré-moldado (mm);

$h=$ altura do consolo metálico (mm); e

$t=$ espessura do consolo metálico (mm).

\section{Dente metálico}

O manual do PCI (PRECAST..., 2010) apresenta dois tipos de ligações Hanger: "Cazaly Hanger" e “Loov Hanger”. Na conexão Hanger, o elemento de suspensão utilizado como apoio nas peças prémoldadas é o aço em vez do concreto. Esse tipo de ligação tem sido utilizado quando se deseja manter um nivelamento de topo entre os elementos conectados.

Na ligação Cazaly Hanger utilizada como suporte provisório, além do perfil metálico em balanço, existe uma cinta e barras de aço soldadas na parte superior e inferior do perfil. O perfil metálico serve como suporte principal do elemento, enquanto a cinta transfere as forças verticais para o perfil. As barras inferiores fornecem ancoragem no concreto para a cinta a fim de evitar o arrancamento por 
rotação, e a barra superior auxilia na transferência de qualquer esforço horizontal para o resto dos componentes (Figura 4a). As Equações (7) a (14) encontradas no PCI (PRECAST..., 2010) são utilizadas no dimensionamento da ligação Cazaly Hanger, e a Figura 4b apresenta a ilustração da nomenclatura utilizada. El Debs (2000) relata que a formulação também pode ser empregada quando se utilizam barras de aço em vez de chapas de aço na composição da cinta metálica.

O perfil metálico deve ser dimensionado de modo que a reação no interior do concreto seja igual a 0,33 $V_{u}$, enquanto a cinta metálica deve ser dimensionada para uma força de $1,33 V_{u}$. A Equação (6) fornece o valor da área de aço necessária para a cinta metálica.

$$
A_{s}=\frac{1,33 V_{u}}{f_{y d}}
$$

Onde:

$A_{s}=$ área de aço que compõe a cinta metálica $\left(\mathrm{mm}^{2}\right)$;

$V_{u}=$ força cortante no dente com seu valor de cálculo $(\mathrm{kN})$; e

$f_{y d}=$ resistência de cálculo ao escoamento do aço que forma a cinta metálica (MPa).

O cálculo do momento no perfil metálico em balanço $\left(M_{u}\right)$ é feito em função da força cortante $\left(V_{u}\right)$ com uma excentricidade " $a$ ” e da força axial
$\left(N_{u}\right)$ com uma excentricidade “0,5h” (PRECAST..., 2010).

$M_{u}=V_{u} a+N_{u} a+N_{u}(0,5) h$

$a=0,5 l_{p}+g+c+(0,5) S_{w}$

Onde:

$h=$ altura do dente metálico (mm);

$l_{p}=$ comprimento em balanço do dente metálico (mm);

$g$ = distância da face do suporte até o elemento suportado (mm);

$c=$ cobrimento do concreto (mm); e

$S_{w}=$ largura da cinta metálica utilizada na ligação (mm).

O módulo de resistência plástico mínimo que deve ter o perfil ou a seção estrutural vazada pode ser determinado de acordo com a Equação (9) (PRECAST..., 2010).

$Z_{p}=\frac{M_{u}}{f_{y d}}$

Onde:

$Z_{p}=$ módulo de resistência plástico do aço $\left(\mathrm{mm}^{3}\right)$; $\mathrm{e}$

$f_{y d}=$ resistência de cálculo ao escoamento do aço (MPa).

Figura 4 - Ilustração da nomenclatura utilizada no projeto da ligação do tipo Cazaly Hanger e concepção do modelo

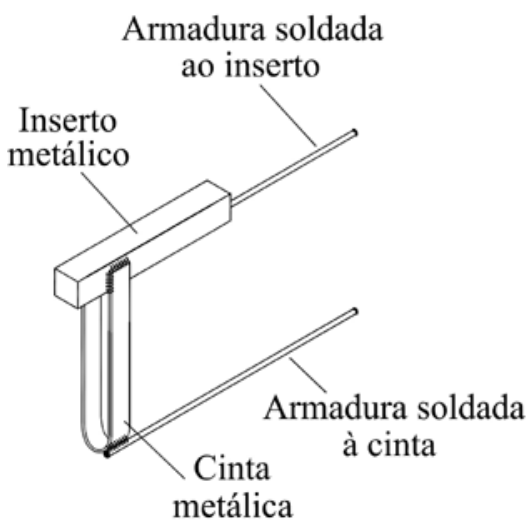

Fonte: adaptada de PCI (PRECAST..., 2010).

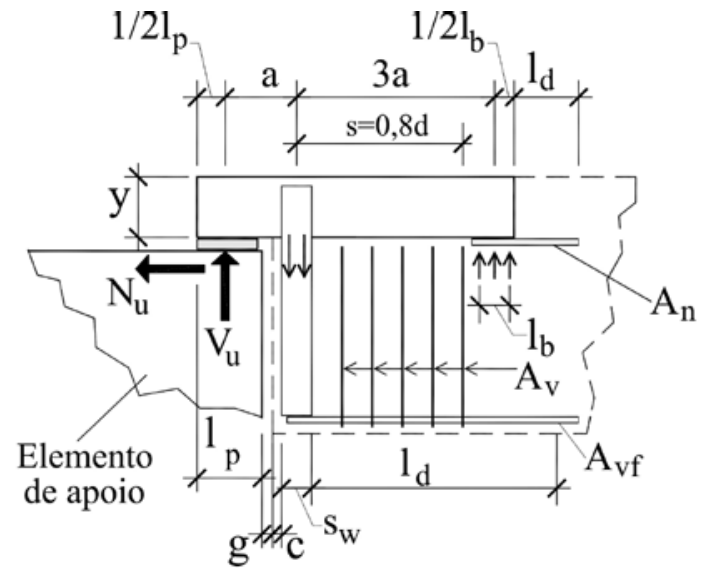

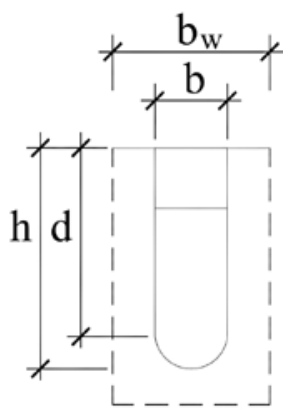

O cálculo dos estribos, distribuídos uniformemente ao longo da distância 0,8 d, como ilustrado na Figura 4, para resistir à força de $1,33 V_{u}$, pode ser determinado de acordo com a Equação (10), e a verificação da área mínima requerida é feita de acordo com a Equação (11) (PRECAST..., 2010).

$$
\begin{aligned}
& A_{v}=\frac{1,33 V_{u}}{f_{y d}} \\
& A_{v}=1,96 \sqrt{f_{c d}} \frac{b_{w} s}{f_{s d}}
\end{aligned}
$$

Eq. 11 
Onde:

$A_{v}=$ área da armadura dos estribos $\left(\mathrm{mm}^{2}\right)$;

$f_{c d}=$ resistência de cálculo à compressão do concreto (MPa);

$b_{w}=$ largura da seção transversal da viga prémoldada $\left(\mathrm{mm}^{2}\right)$;

$s=$ distância entre o centro da cinta metálica e o último estribo (mm); e

$f_{\text {sd }}=$ resistência de cálculo ao escoamento da armadura de aço (Mpa).

As Equações (12) e (13) apresenta o cálculo do comprimento necessário do perfil para manter as condições de equilíbrio.

$$
\begin{aligned}
& l=2,5 l_{p}+4 g+4 c+2 S w+0,5 l_{b} \\
& l_{b}=\frac{V_{u}}{1,66 \sqrt{\frac{b_{w}}{b}}}
\end{aligned}
$$

\section{Programa experimental}

Um pórtico estrutural com a ligação provisória em estudo foi montado no laboratório (Figura 5), em escala 1:3, para verificar os esforços e determinar a resistência do consolo e dente metálico do tipo A.

Os componentes da ligação, consolo e dente metálico foram confeccionados com espessuras de chapas de aço diferenciadas para induzir a ruína dos elementos de forma controlada. Em uma extremidade do pórtico, para ocasionar a ruína do consolo metálico, o dente metálico foi confeccionado com chapa de aço de $12,5 \mathrm{~mm}$ de espessura (dente metálico do tipo B), e o consolo metálico tinha uma chapa com espessura de 7,5 mm (consolo metálico do tipo A). Na outra extremidade do pórtico, para ocasionar a ruína do dente metálico, o consolo metálico foi confeccionado com chapa de aço de espessura igual a 12,5 mm (consolo metálico do tipo B), e o dente metálico tinha uma chapa com espessura de 7,5 mm (dente metálico do tipo A). A
Figura 6 mostra as características das peças constituintes do pórtico estrutural.

O consolo metálico consiste de um perfil de seção do tipo "U" formado por chapas de aço estrutural ASTM A36, sendo que a união das chapas de aço se deu por meio de solda filete do tipo MIG. Em cada lateral do consolo metálico foram soldados dois vergalhões com diâmetro de $12,50 \mathrm{~mm}$ e comprimento total de $1.000 \mathrm{~mm}$. O consolo metálico possui altura de $150 \mathrm{~mm}$, largura de 120 mm e comprimento total de $750 \mathrm{~mm}$, no qual 300 mm do comprimento total ficaram salientes ao pilar para o encaixe do dente metálico (Figura 7). O dente metálico, de seção retangular vazada, tem espessura de 7,5 mm e é formado de aço estrutural ASTM A36, com altura de $140 \mathrm{~mm}$, largura de $75 \mathrm{~mm}$ e comprimento total de $1.200 \mathrm{~mm}$. Nas laterais do dente metálico foram soldados dois vergalhões de aço em formato de "U" com diâmetro de 12,50 mm, que serviu como cinta metálica, e na cinta metálica foram soldados dois vergalhões com diâmetro de $12,50 \mathrm{~mm}$. Também foi soldado na face inferior do dente metálico um vergalhão com diâmetro de 12,50 mm (Figura 8).

A força aplicada no pórtico estrutural durante a execução do ensaio se deu por meio do atuador servocontrolado com controle de deslocamento do pistão e velocidade de $0,005 \mathrm{~mm} / \mathrm{s}$, em que há uma célula de carga para determinar os valores referentes à força aplicada. O valor-limite de aplicação da força na viga foi determinado através da leitura parcial dos extensômetros colados no dente e no consolo metálico do tipo A, força cessada quando alguns dos extensômetros já haviam atingido o fundo de escala. As reações na ligação foram determinadas com base em seu comprimento de $500 \mathrm{~mm}$ e desconsiderando a atuação do peso próprio. A ligação em estudo é considerada como sendo de primeiro gênero, pois não houve ação da força horizontal durante o ensaio e as possíveis variações de comprimento são desprezíveis em função do tempo do ensaio e das condições de laboratório.

\section{Figura 5 - Perspectiva isométrica do pórtico estrutural}

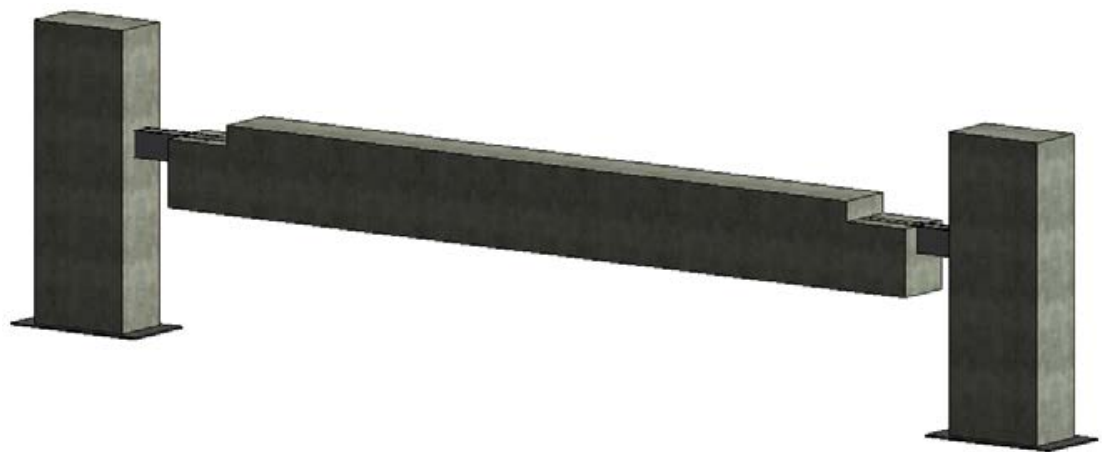


Figura 6 - Geometria dos pilares e viga utilizados no ensaio (dimensões em $\mathbf{m m}$ )
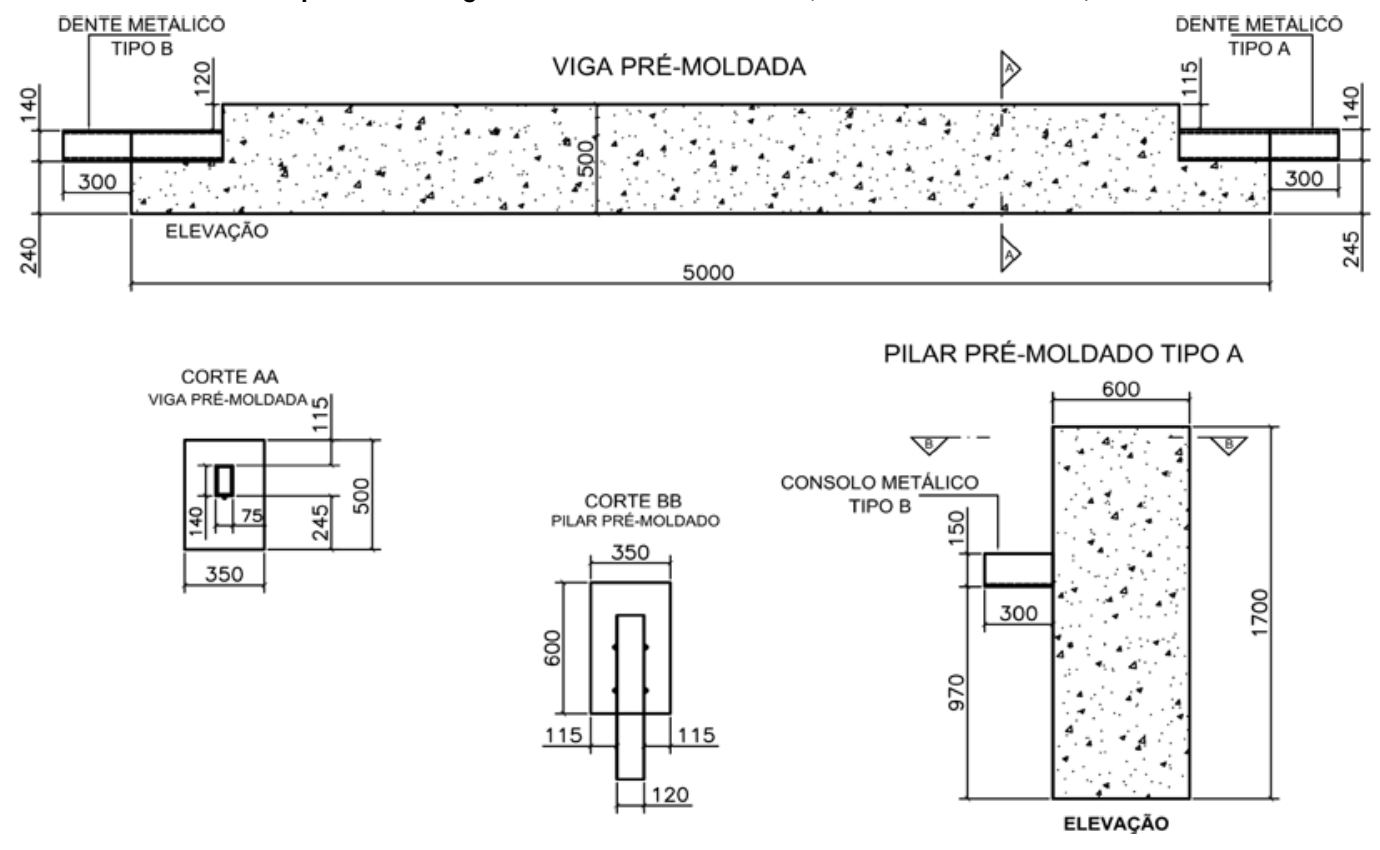

Figura 7 - Geometria e vista isométrica do consolo metálico do tipo A (dimensões em $\mathrm{mm}$ )

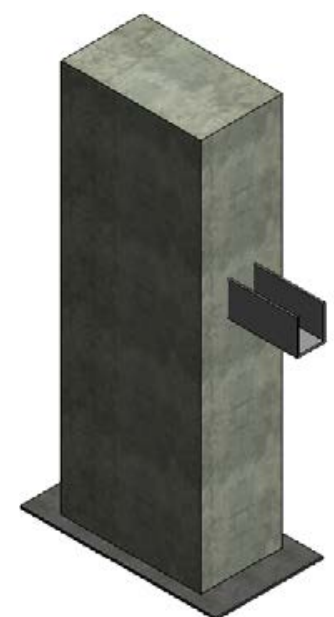

(a) Extremidade do pilar com consolo metálico

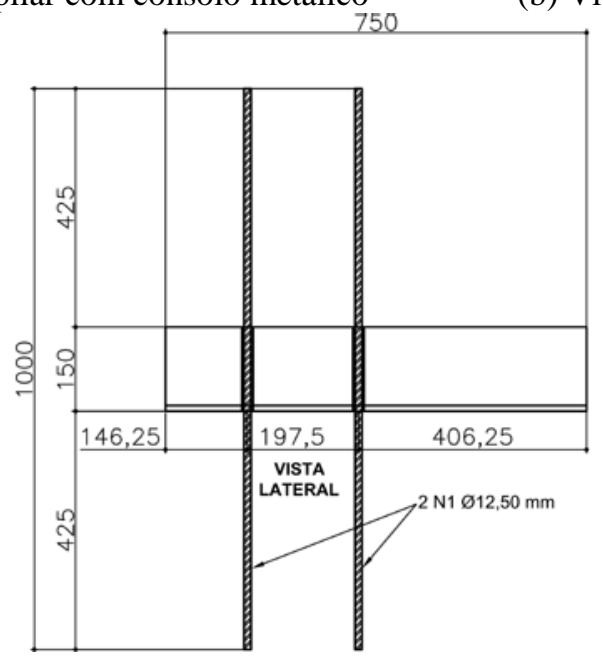

(c) Geometria do consolo metálico

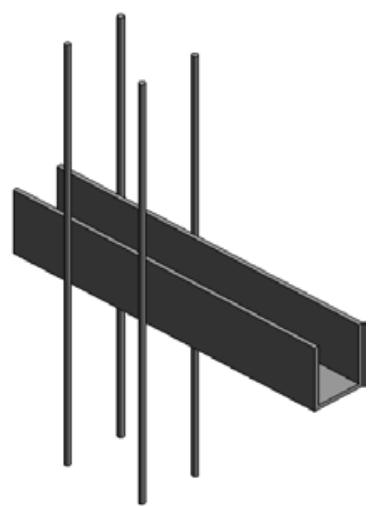

(b) Vista isométrica do consolo metálico 
Figura 8 - Geometria e vista isométrica do dente metálico do tipo A (dimensões em mm)

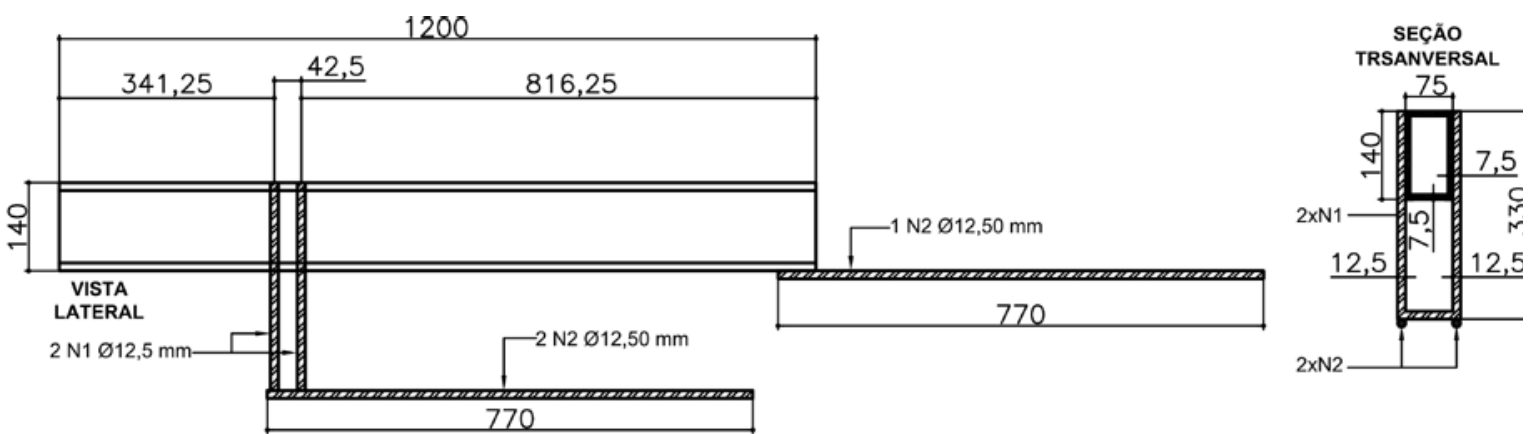

(a) Geometria do dente metálico do tipo A

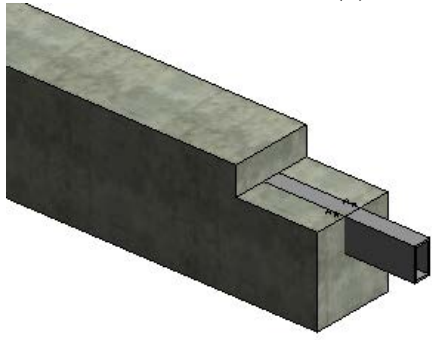

(b) Extremidade da viga com o dente metálico

O consolo e o dente metálico foram instrumentados com extensômetros elétricos de resistência para determinar a deformação da ligação, bem como para caracterizar sua forma de ruína. Nas Figuras 9 e 10 estão apresentadas as posições dos extensômetros no consolo e no dente metálico respectivamente.

A primeira etapa do ensaio foi realizada para analisar o dente metálico do tipo A. O atuador servocontrolado foi posicionado sobre o pórtico estrutural a $1.700 \mathrm{~mm}$ da extremidade da viga $(0,34$ do vão), conforme apresentado na Figura 11, e a força máxima aplicada foi de 349,6 kN. Como os apoios são caracterizados como sendo de primeiro gênero, a reação na extremidade da viga com dente do tipo A foi de $230,7 \mathrm{kN}$, e na extremidade da viga com dente do tipo B (Figura 6) o valor obtido foi de $118,9 \mathrm{kN}$.

$\mathrm{Na}$ segunda etapa do carregamento objetivou-se analisar o consolo metálico do tipo A. Nesse caso, o atuador foi deslocado para a extremidade oposta à força aplicada na primeira etapa, distando $700 \mathrm{~mm}$ da face da viga pré-moldada (Figura 12). O valorlimite da força aplicada no pórtico estrutural foi de 364,8 kN, e, como a ligação nessa extremidade também é de primeiro gênero, as reações encontradas para a força aplicada na viga foram de

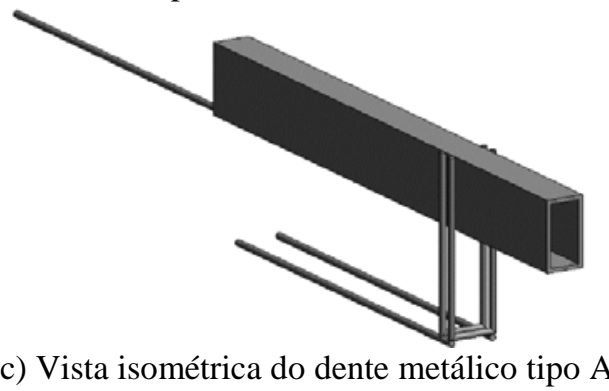

(c) Vista isométrica do dente metálico tipo A

313,7 kN no lado da viga com dente do tipo B e de $51,1 \mathrm{kN}$ no lado da viga com dente do tipo A (Figura 6).

As Tabelas 1 e 2 apresentam as variáveis utilizadas na formulação do consolo e do dente metálico do tipo A. Na Tabela 3 estão discriminados os valores médios dos resultados obtidos da caracterização do concreto, vergalhões e chapas de aço considerados na formulação do dente e do consolo metálico do tipo A. Para a caracterização das barras e chapas de aço foram ensaiados três corpos de prova de cada material analisado, exceto na determinação do módulo de elasticidade do aço, na qual foi adotado o valor proposto pela NBR 8800 (ABNT, 2008). Na caracterização do concreto do pilar e da viga ensaiaram-se cinco corpos de prova no dia da execução do ensaio no pórtico estrutural.

\section{Análise dos resultados}

A verificação analítica utilizando as equações citadas no modelo analítico do consolo e dente metálico foi realizada sem considerar os coeficientes de majoração das ações e os coeficientes de minoração dos materiais, no intuito de determinar a força resistente atuante no elemento e comparar com os resultados experimentais. 
Figura 9 - Posicionamento dos extensômetros no consolo metálico do tipo A

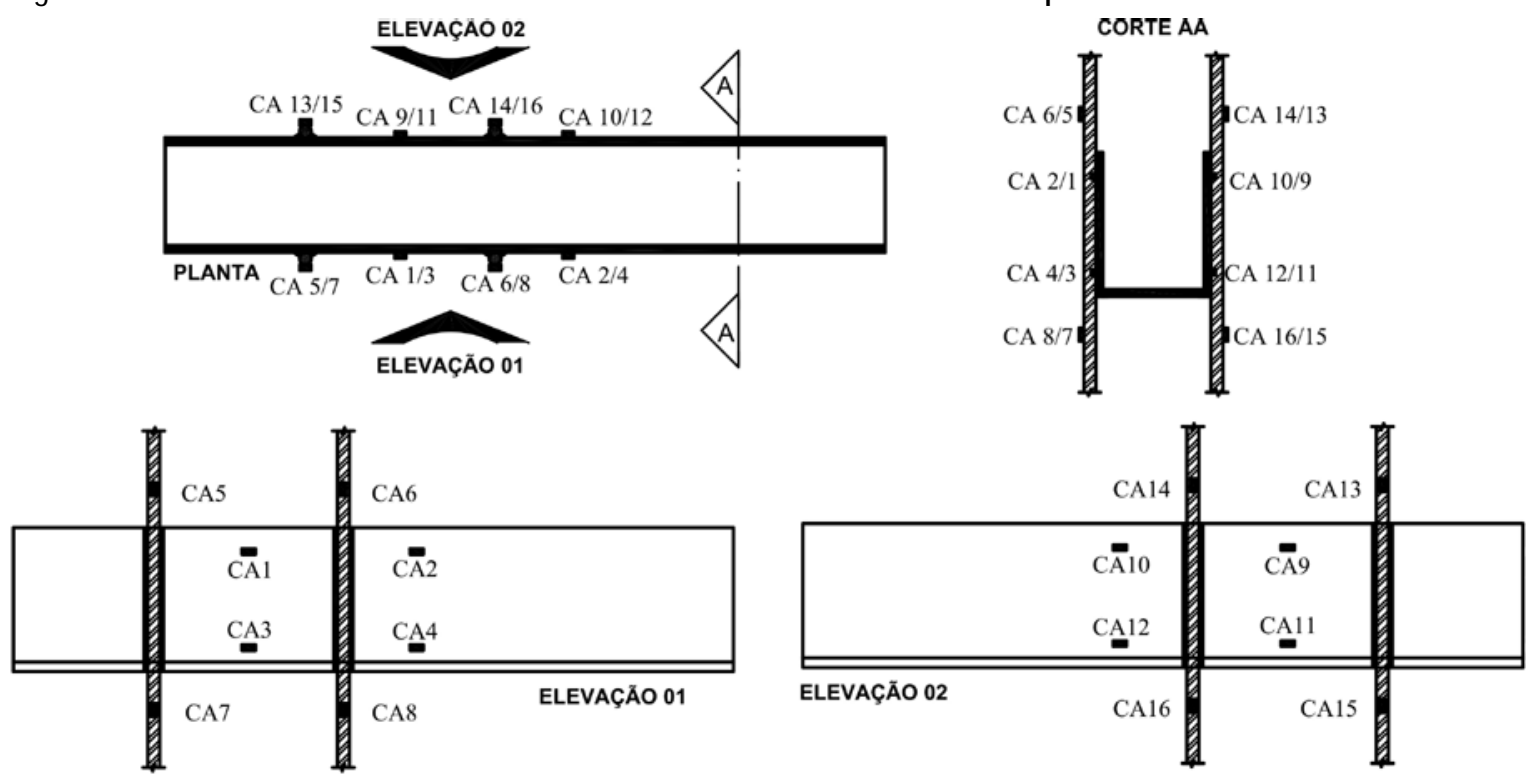

Figura 10 - Posicionamento dos extensômetros no dente metálico do tipo A

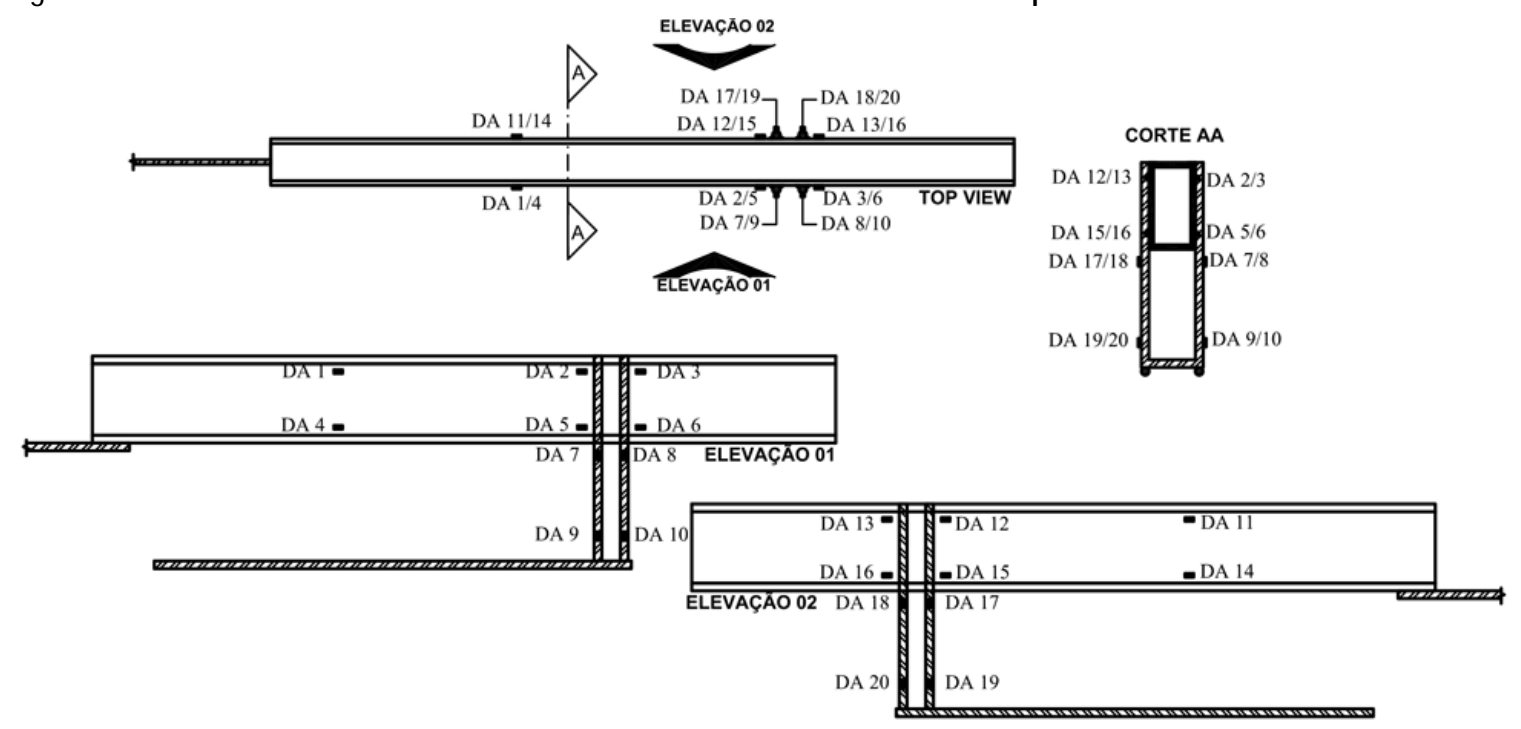

Figura 11 - Esquema de aplicação do carregamento no pórtico estrutural para análise do dente metálico
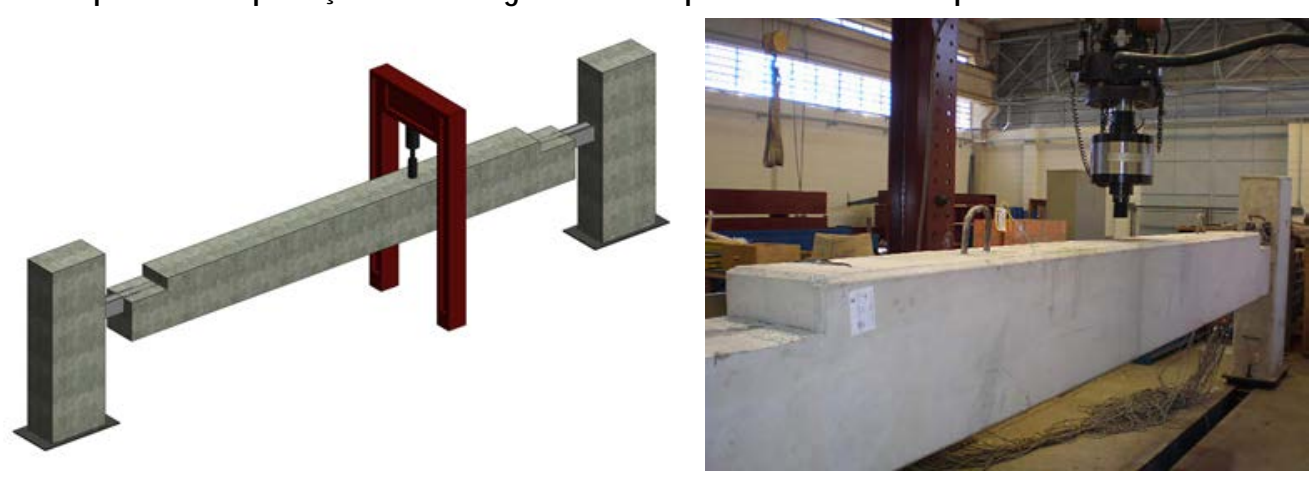
Figura 12 - Esquema de aplicação do carregamento no pórtico estrutural para análise do consolo metálico do tipo $\mathrm{A}$
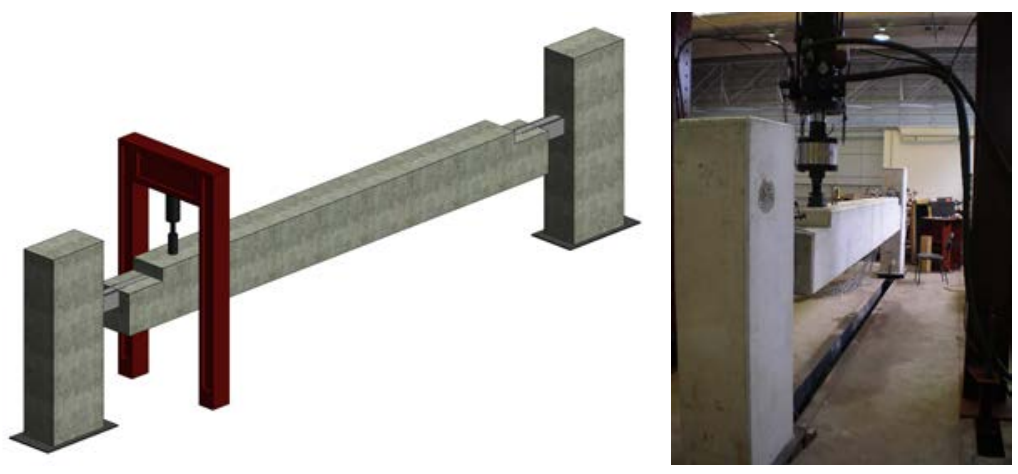

Tabela 1 - Variáveis adotadas na formulação do consolo metálico do tipo A (ver Figura 3)

\begin{tabular}{c|c}
\hline Variável & Valor adotada \\
\hline$b$ & $300 \mathrm{~mm}$ \\
$l_{e}$ & $450 \mathrm{~mm}$ \\
$e$ & $375 \mathrm{~mm}$ \\
$s$ & $197,5 \mathrm{~mm}$ \\
$a$ & $150 \mathrm{~mm}$ \\
\hline
\end{tabular}

Tabela 2 - Variáveis adotadas na formulação do dente metálico do tipo A (ver Figura 4)

\begin{tabular}{c|c}
\hline Variável & Valor arbitrado \\
\hline$l_{p}$ & $300 \mathrm{~mm}$ \\
$g$ & $10 \mathrm{~mm}$ \\
$c$ & $25 \mathrm{~mm}$ \\
$S_{w}$ & $25 \mathrm{~mm}$ \\
$b$ & $75 \mathrm{~mm}$ \\
$b_{w}$ & $35 \mathrm{~mm}$ \\
$a$ & $210 \mathrm{~mm}$ \\
\hline
\end{tabular}

Tabela 3 - Parâmetros relativos aos materiais empregados na ligação

\begin{tabular}{l|c}
\hline Resistência ao escoamento do aço da armadura $\varnothing 12,5 \mathrm{~mm}$ & $569 \mathrm{MPa}$ \\
\hline Resistência ao escoamento do aço do perfil & $267 \mathrm{MPa}$ \\
\hline Resistência média à tração do concreto da viga aos 72 dias & $3,94 \mathrm{MPa}$ \\
\hline Resistência média à tração do concreto do pilar aos 79 dias & $3,98 \mathrm{MPa}$ \\
\hline Resistência média à compressão do concreto da viga aos 72 dias & $53,67 \mathrm{MPa}$ \\
\hline Resistência média à compressão do concreto do pilar aos 79 dias & $52,03 \mathrm{MPa}$ \\
\hline$\left(f_{y} / E\right)_{\text {perfil }}$ & $0,13 \%$ \\
$\left(f_{y} / \mathrm{E}\right)_{\text {armadura }}$ & $0,29 \%$ \\
\hline
\end{tabular}

As Tabelas 4 e 5 apresentam os resultados da verificação analítica feita no consolo e no dente metálico do tipo A respectivamente. Os valores das resistências dos materiais utilizados no dimensionamento foram obtidos do ensaio de caracterização e estão apresentados na Tabela 3 . Além da formulação apresentada pelo PCI (PRECAST..., 2010) para o modelo de cálculo, também foram utilizadas fórmulas complementares demonstradas na NBR 8800 (ABNT, 2008) para auxiliar no dimensionamento dos elementos consolo e dente metálico (ver desenvolvimento em Prado (2014)).

Com base nos resultados apresentados, foi possível determinar que as principais formas de ruína para o consolo metálico foram ruptura do concreto, plastificação e cisalhamento do perfil metálico (Tabela 4). Já para o dente metálico as principais formas de ruína são escoamento do aço da cinta metálica e plastificação do perfil metálico (Tabela 5). 
A Figura 13 apresenta as curvas da força na ligação versus deformação dos extensômetros localizados nas chapas e vergalhões de aço do consolo metálico do tipo A referente à segunda etapa de carregamento.

Pela análise das curvas (Figura 13) pode-se notar que os extensômetros que atingiram deformações maiores que a deformação de escoamento da chapa de aço $(0,13 \%)$ foram CA2, CA10, CA4 e CA12 (Figura 9). Os extensômetros CA4 e CA12 apresentaram deformações negativas, o que indica que essa região estava comprimida. O extensômetro CA4 atingiu a deformação de escoamento para uma reação na ligação de 297 kN, e o extensômetro CA12 escoou com a reação na ligação igual a 304,4 kN. Fazendo uma média desses dois valores, obtémse uma reação de $300,7 \mathrm{kN}$, ou seja, $37,9 \%$ maior que o valor da resistência referente à plastificação total da seção determinada no modelo analítico, 218 $\mathrm{kN}$. Sendo o momento último do consolo metálico praticamente igual ao momento fletor de plastificação, e como os extensômetros CA4 e CA12 estavam posicionados em uma região próxima à seção do momento fletor de plastificação, a reação de $300,7 \mathrm{kN}$ pode ser considerada para o momento último no consolo metálico. Essa diferença de resultados pode ter sido gerada pelo fato de que, nos cálculos analíticos, a reação de apoio foi considerada como sendo aplicada no meio do vão do consolo metálico, e durante a execução do ensaio ela deve ter sido deslocada para a face do pilar, próximo a região de engastamento da ligação, reduzindo a distância do ponto de aplicação da força e a região de engastamento, aumentando a capacidade da ligação.

Em relação aos extensômetros CA2 e CA10, posicionados na parte superior do perfil, as deformações obtidas (Figura 13) mostram que a fibra superior do consolo estava tracionada. O extensômetro CA2 atingiu a deformação de escoamento para uma reação na ligação igual a 155 kN, e o extensômetro CA10 escoou com uma reação na ligação de 171,8 kN. Pelo modelo teórico, a força relativa ao início do escoamento da seção é igual a $141 \mathrm{kN}$. Considerando a média dos valores das reações na ligação correspondente ao início do escoamento, chega-se a $163,4 \mathrm{kN}$, ou seja, $15,8 \%$ maior do que o valor teórico, o que indica coerência nos resultados.

Os extensômetros CA5, CA6, CA7, CA8, CA13, CA14, CA15 e CA16, localizados nos vergalhões de aço do consolo metálico (Figura 9), não registraram deformações maiores que a deformação média de escoamento do aço (0,29\%), conforme pode ser visto nas curvas da Figura 13. Apesar disso, obtiveram pequenas deformações residuais depois que o carregamento foi cessado.

Já os extensômetros CA6, CA14, CA8 e CA16, localizados próximos à região onde a solicitação à flexão foi elevada, obtiveram deformações residuais maiores que os extensômetros CA5, CA13, CA7 e CA15, que estavam próximos da região onde as tensões geradas pela flexão foram menores.

Tabela 4 - Resistência teórica do consolo metálico A com base na formulação do PCI (PRECAST..., 2010) e na NBR 8800 (ABNT, 2008)

\begin{tabular}{l|c}
\hline \multicolumn{1}{c|}{ Elemento resistente do dente metálico do tipo A } & Valor \\
\hline Força resistida pelo concreto e pelas armaduras adicionais soldadas no consolo & $1.593,22 \mathrm{kN}$ \\
Perfil metálico: plastificação total da seção transversal por solicitação normal & $218 \mathrm{kN}$ \\
$\begin{array}{l}\text { Perfil metálico: início de escoamento por solicitação normal } \\
\text { Perfil metálico: solicitação tangencial }\end{array}$ & $141 \mathrm{kN}$ \\
\hline $\begin{array}{l}\text { Resistência da ligação (plastificação total da seção transversal por } \\
\text { solicitação normal) }\end{array}$ & $\mathbf{2 1 8} \mathbf{k N}$ \\
\hline
\end{tabular}

Tabela 5 - Resistência teórica do dente metálico A com base na formulação do PCI (PRECAST..., 2010) e na NBR 8800 (ABNT, 2008)

\begin{tabular}{l|c}
\hline \multicolumn{1}{c|}{ Elemento resistente do consolo metálico do tipo A } & Valor \\
\hline Escoamento da cinta metálica & $210 \mathrm{kN}$ \\
$\begin{array}{l}\text { Perfil metálico: plastificação total da seção transversal por solicitação normal } \\
\text { Perfil metálico: início de escoamento por solicitação normal }\end{array}$ & $180 \mathrm{kN}$ \\
\hline $\begin{array}{l}\text { Resistência da ligação (plastificação total da seção transversal por } \\
\text { solicitação normal) }\end{array}$ & $\mathbf{1 8 0 ~ k N}$ \\
\hline
\end{tabular}


Figura 13 - Força na ligação versus deformação no consolo metálico do tipo A
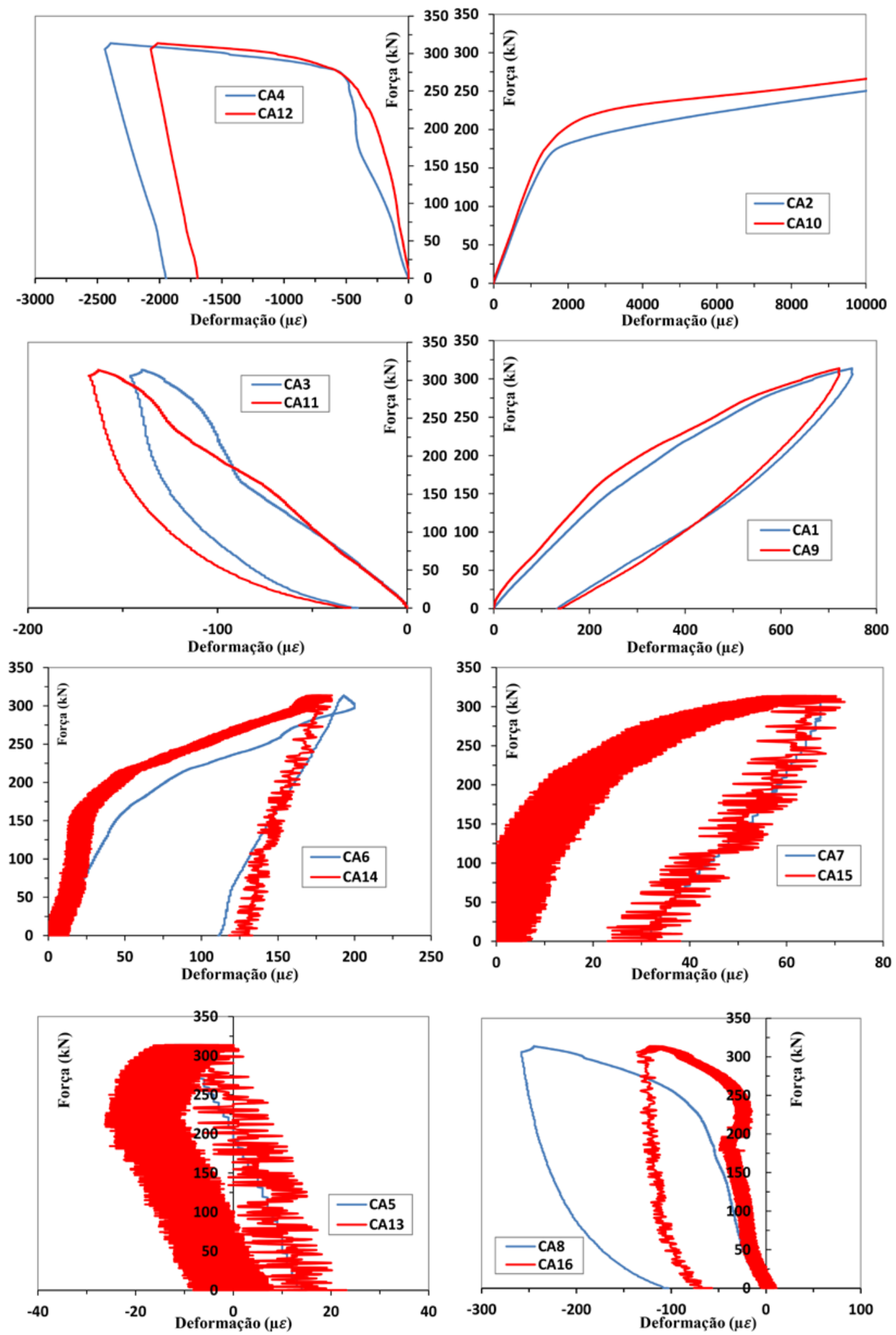
Em relação aos extensômetros CA1, CA9, CA3 e CA11, posicionados nas chapas de aço do consolo metálico (Figura 9), não se observaram deformações de escoamento maiores que a deformação de escoamento da chapa de aço, conforme mostram as curvas da Figura 13. Quando o carregamento foi cessado, os extensômetros apresentaram pequenas deformações residuais, que podem ter sido ocasionadas pelas deformações plásticas geradas na região próxima a esses extensômetros.

Pelo resultado das curvas (Figura 13), os extensômetros CA1 e CA9 exibiram uma deformação residual, pois eles estavam posicionados próximos da região de maior solicitação à tração com maior deformação, conforme pode ser visto na leitura dos extensômetros CA2 e CA10. Já os extensômetros CA3 e CA11 apresentaram deformações residuais bem pequenas, visto que eles estavam posicionados na região inferior, onde a plastificação ocorreu no fim do carregamento, gerando pequenas deformações.

Após a aplicação do carregamento foi medido um deslizamento de $10 \mathrm{~mm}$ do consolo metálico para fora do concreto, conforme pode ser visto na Figura 14, ocasionando o aparecimento de fissuras nessa região (Figura 15). Diante dessa situação, pode-se constatar que a forma de ruína do consolo ocorreu pelo escoamento do perfil, sendo que ele escorregou para fora do concreto, gerando tensões excessivas na face superior do consolo metálico do tipo A.

A Figura 16 apresenta as curvas da força na ligação versus deformação dos extensômetros localizados nas chapas e vergalhões de aço do dente metálico do tipo A (Figura 10) referente à primeira etapa de aplicação da força. Não foi possível plotar a curva de alguns dos extensômetros, pois eles apresentaram falhas durante a execução do ensaio.

De acordo com as curvas apresentadas na Figura 16, pode-se notar que os extensômetros DA2, DA12, DA3 e DA13 (Figura 10) foram comprimidos, pois sofreram deformações negativas, sendo esses valores maiores que a deformação de escoamento da chapa de aço $(0,13 \%)$, visto que, quando o carregamento foi cessado, a chapa de aço apresentou uma deformação residual, indicando a plastificação do material. O extensômetro DA2 escoou quando a reação na ligação foi de $211,2 \mathrm{kN}$, e o extensômetro DA12 escoou com uma reação na ligação de 217,8 kN. Além disso, os extensômetros
DA3 e DA13 (Figura 10) atingiram o escoamento do aço quando a reação na ligação foi de 201,3 kN.

Os extensômetros DA5 e DA15 (Figura 10) também atingiram a deformação de escoamento do aço para uma reação na ligação de 210,5 kN, enquanto o extensômetro DA6 escoou quando a reação na ligação foi de 231 kN. Esses extensômetros forneceram valores positivos de deformação, indicando que estavam sendo tracionados. Comparando a deformação plástica residual do extensômetro DA6 com o DA5, posicionado ao lado, é possível ver que ele ultrapassou muito pouco a tensão de escoamento do aço, e pode ter ocorrido uma perturbação de tensões nessa região em que estava posicionado o extensômetro DA6, o que causou a diferença de resultado dos demais.

A média das reações na ligação referente ao escoamento dos extensômetros posicionados na parte superior do dente foi igual a $207,9 \mathrm{kN}$, e dos extensômetros posicionados na região inferior foi de 217,33 kN. Pelo modelo analítico, a força máxima resistida pelo perfil metálico associada ao momento fletor de plastificação foi de $180 \mathrm{kN}$, e em relação ao momento fletor de início de escoamento, 132 kN. O resultado experimental da reação na ligação referente ao momento fletor de início de escoamento foi $57,5 \%$ superior ao valor calculado analiticamente para os extensômetros posicionados na parte superior e 64,6\% para os extensômetros posicionados na região inferior. $\mathrm{O}$ valor médio da deformação correspondente ao momento fletor de início de escoamento (momento referente ao final da fase elástica) é de $61,1 \%$.

A força encontrada no modelo experimental para o dente metálico foi bem maior em relação ao valor determinado analiticamente. Essa diferença de valores pode ter sido ocasionada pela posição da reação de apoio atuante no dente metálico, e na expressão proposta pelo modelo analítico do PCI (PRECAST..., 2010) ela é considerada como sendo aplicada no meio do dente metálico; no modelo experimental, deve ter ocorrido um deslocamento da reação de apoio para a face da viga, reduzindo a distância entre o ponto de aplicação da força e a região de engastamento.

O valor médio da reação que gerou tração na face inferior do dente metálico foi semelhante ao valor médio da reação que gerou compressão na face superior, o que confirma a hipótese de simetria da seção transversal. 
Figura 14 - Deslizamento do consolo metálico do tipo A do concreto

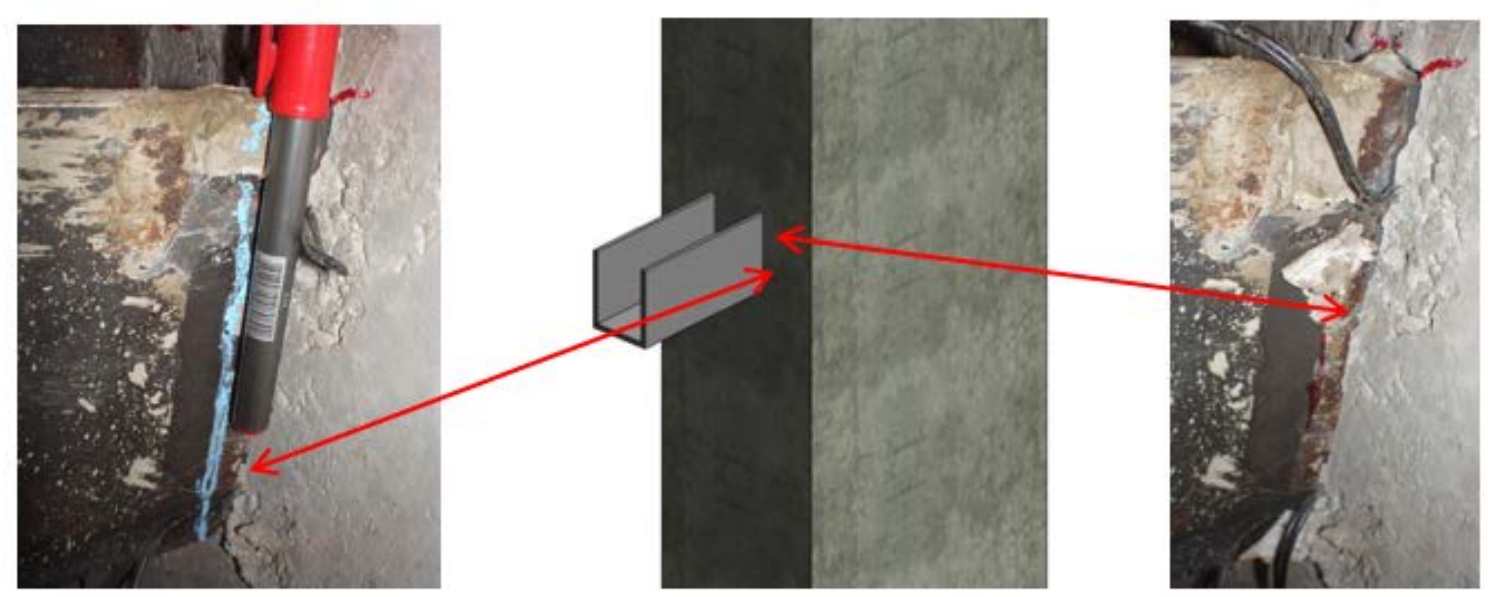

(a) Deslizamento do consolo metálico

(b) Perspectiva da foto tirada

(c) Deslizamento do consolo metálico

Figura 15 - Marcação de fissuras junto à borda do consolo metálico do tipo A

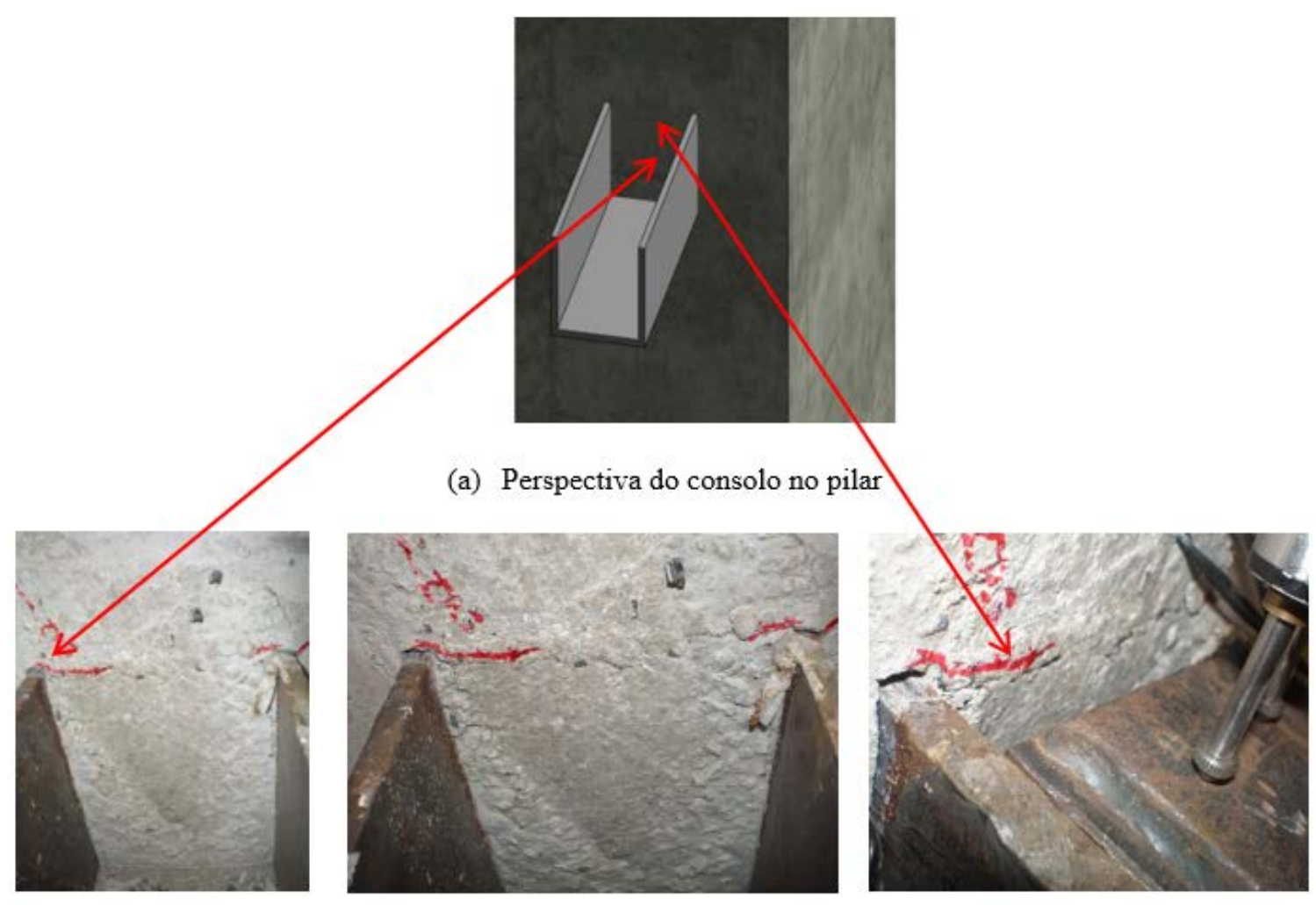

(b) Formação de fissuras na borda do consolo metálico 
Figura 16 - Força na ligação versus deformação no dente metálico do tipo A
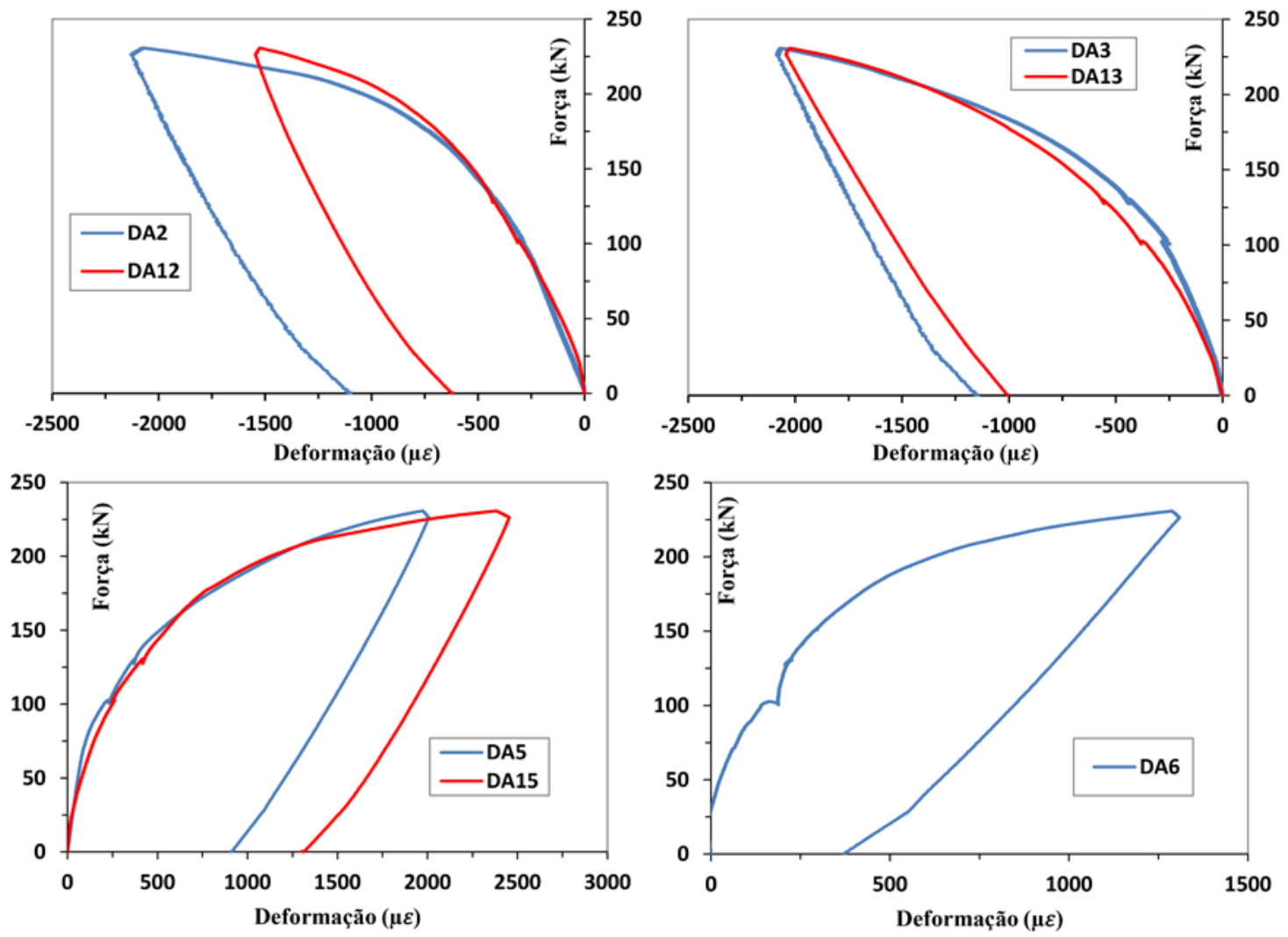

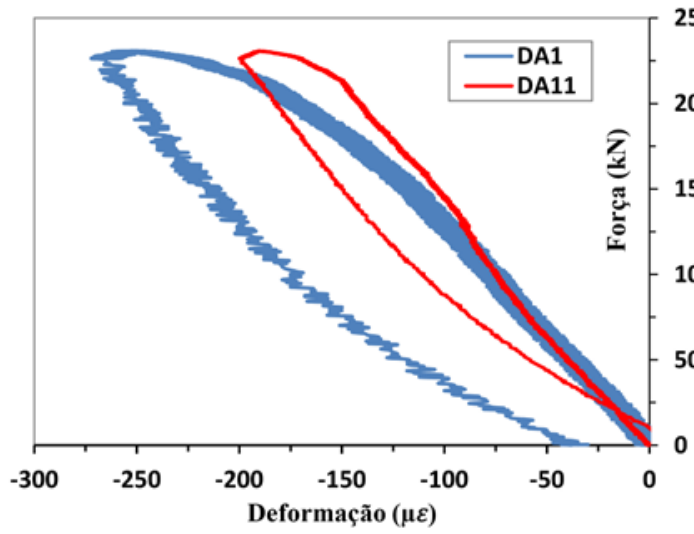

Pela análise das curvas na Figura 17 observa-se que os extensômetros DA8, DA18, DA7 e DA17, posicionados nos vergalhões de aço que formam a cinta metálica (Figura 10), obtiveram deformações maiores que a deformação de escoamento do aço (0,29\%). Os extensômetros DA8 e DA18 escoaram com uma reação na ligação de 223 kN e 229,4 kN respectivamente, e os extensômetros DA7 e DA17 escoaram com a reação na ligação de $226,2 \mathrm{kN}$ e $210 \mathrm{kN}$ respectivamente. O valor médio das reações encontradas é de 222,15 kN, ou seja, 5,8\% maior que o determinado no modelo analítico para a cinta metálica, $210 \mathrm{kN}$.

Em vista dos resultados obtidos, pode-se afirmar que o modelo de cálculo proposto para a

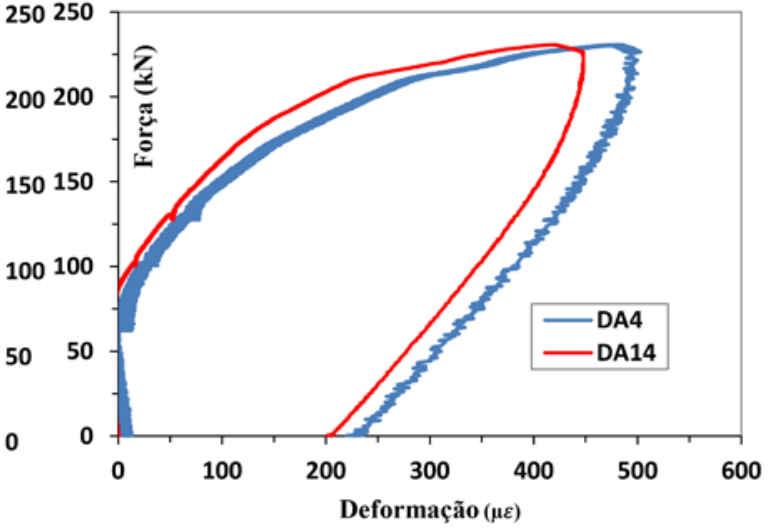

determinação dos esforços na cinta metálica formada por chapas de aço é coerente para ser usado em cinta metálica constituída por vergalhões de aço.

Os extensômetros DA9, DA10, DA19 e DA20, também posicionados na cinta metálica (Figura 10), não atingiram a deformação de escoamento da barra de aço de $ø 12,5 \mathrm{~mm}$, conforme mostram as curvas da Figura 17. Contudo, foram observadas deformações residuais nesses extensômetros, quando cessada a força aplicada na viga, que podem ter sido ocasionadas pela distribuição de tensões excessivas na parte superior da cinta metálica, o que é notado nos resultados obtidos dos extensômetros DA8, DA18, DA7 e DA17. 
Figura 17 - Força na ligação versus deformação nos vergalhões do dente metálico do tipo A
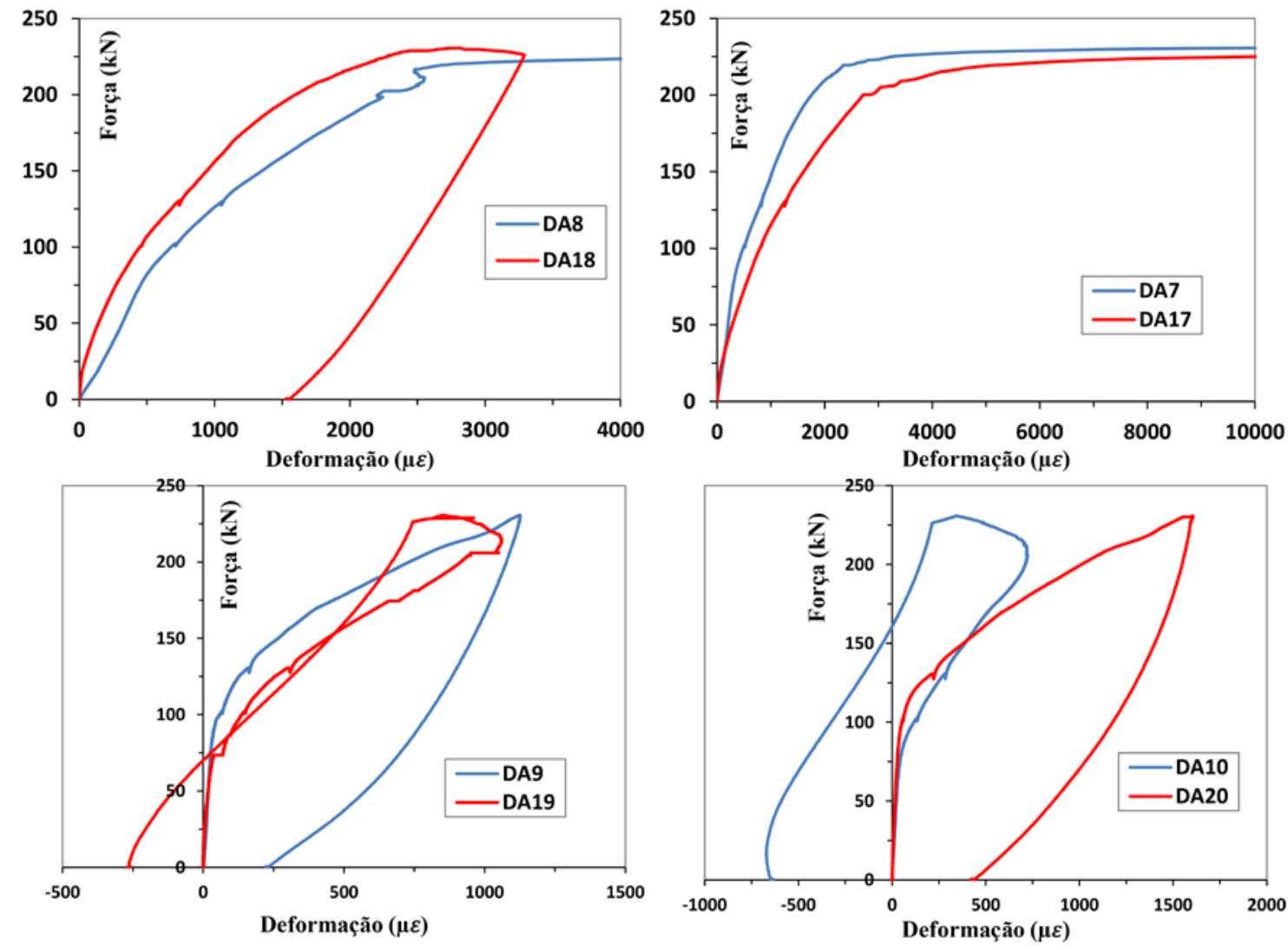

Os extensômetros posicionados na parte inferior da cinta metálica apresentaram deformações inferiores em relação aos posicionados na parte superior dela. Essa diferença de valores pode ter sido causada pelo fato de eles estarem localizados em uma região de perturbação, próximo ao nó, onde há transição dos esforços.

\section{Conclusões}

Algumas conclusões estão elencadas a seguir.

(a) no modelo analítico, a reação de apoio foi considerada no meio do vão da ligação, no entanto, como os resultados experimentais, tanto para o consolo quanto para o dente metálico, foram superiores aos resultados obtidos analiticamente, deve-se concluir que, à medida em que os perfis metálicos foram plastificando, a força deve ter sido deslocada para a região próxima ao engastamento da ligação, aumentando a capacidade da ligação;

(b) a força resistente do dente metálico, determinada analiticamente, correspondeu à plastificação total da seção transversal do perfil de aço por solicitação normal. Em relação ao momento fletor de início de escoamento (momento referente ao final da fase elástica), o resultado obtido experimentalmente foi $61,1 \%$ superior em

relação ao valor determinado analiticamente. Destaca-se que parte dessas diferenças se deve à mudança da força resultante durante o ensaio, que aumentou a resistência do dente metálico;

(c) o valor da reação na ligação encontrado experimentalmente referente ao momento último foi 37,9\% superior ao modelo teórico. Já para o momento fletor de início de escoamento (momento referente ao final da fase elástica), o resultado experimental foi $15,8 \%$ maior que o determinado analiticamente. Novamente se salienta que essa diferença se deve à mudança da força resultante durante a execução do ensaio;

(d) de acordo com o manual do PCI

(PRECAST..., 2010), a parcela resistida pela cinta metálica formada por chapas de aço é de 1,33 vez a força última da ligação. Esse valor foi determinado com base na posição da cinta em relação ao comprimento do dente metálico, partindo do princípio de equilíbrio de corpo rígido (ver desenvolvimento em Prado, 2014). Na geometria do dente metálico estudado, a relação obtida analiticamente foi de 1,26, valor igual à relação encontrada experimentalmente, o que comprova a proporcionalidade entre a cinta e o dente metálico; 
(e) os vergalhões de aço soldados lateralmente ao consolo metálico atingiram deformações menores que as deformações de escoamento, indicando que não houve contribuição deles. Em vista desses resultados, as armaduras adicionais não devem ser consideradas como parcela resistente no modelo analítico apresentado pelo manual do PCI (PRECAST..., 2010), sendo que ela pode estar soldada lateralmente ao consolo metálico, de modo a servir apenas como uma possível ancoragem; e

(f) o PCI (PRECAST..., 2010) propõe a utilização de chapas metálicas na cinta do dente metálico, e, com o uso dos vergalhões de aço na composição da cinta metálica em vez da chapa de aço, os valores encontrados no ensaio foram próximos aos valores teóricos, o que implica que pode ser feita a troca da chapa pelo vergalhão.

\section{Referências}

ASSOCIAÇÃO BRASILEIRA DE NORMAS TÉCNICAS. NBR 8800: projeto de estruturas de aço e de estruturas mistas de aço e concreto de edifícios. Rio de Janeiro, 2008.

EL DEBS, M. K. Concreto Pré-Moldado: fundamentos e aplicações. São Carlos: EESC-USP, 2000.
OLIVEIRA JÚNIOR, L. A. Ligação Viga-Pilar em Elementos Pré-Moldados de Concreto Solidarizados Por Concreto Reforçado Com Fibras de Aço: análise estática e dinâmica. São Carlos, 2012. 254 f. Tese (Doutorado em Engenharia de Estruturas) - Escola de Engenharia de São Carlos, Universidade de São Paulo, São Carlos, 2012.

PRADO, L. P. Ligações de Montagem VigaPilar Para Estruturas de Concreto PréMoldado: estudo de caso. São Carlos, 2014. 201 f. Dissertação (Mestrado em Engenharia de Estruturas) - Escola de Engenharia de São Carlos, Universidade de São Paulo, São Carlos, 2014.

PRECAST CONCRETE INSTITUTE. Design

Handbook: precast and prestressed concrete. 7. ed. Chicago: Precast/Prestressed Concrete Institute, 2010.

\section{Agradecimentos}

Os autores agradecem a Usicon Construções PréFabricadas, pelas peças pré-moldadas cedidas para a execução do projeto; à agência de fomento Conselho Nacional de Desenvolvimento Científico e Tecnológico (CNPq), por proporcionar o desenvolvimento do projeto; e aos funcionários do Departamento de Estruturas da Escola de Engenharia de São Carlos.

\footnotetext{
Lisiane Pereira Prado

Departamento de Estruturas, Escola de Engenharia de São Carlos | Universidade de São Paulo | Av. Trabalhador Sãocarlense, 400, Centro | São Carlos - SP - Brasil | CEP 13566-590 | Tel.: (18) 98141-0179| E-mail: lisianeprado@usp.br

\section{Mounir Khalil El Debs}

Departamento de Estruturas, Escola de Engenharia de São Carlos | Universidade de São Paulo | Tel.: (16) 3373-9474 | E-mail: mkdebs@sc.usp.br
}

Revista Ambiente Construído

Associação Nacional de Tecnologia do Ambiente Construído

Av. Osvaldo Aranha, 99 - 30 andar, Centro

Porto Alegre - RS - Brasil CEP 90035-190

Telefone: +55 (51) 3308-4084

Fax: +55 (51) 3308-4054

www. seer. ufrgs. br/ ambienteconstruido

E-mail: ambienteconstruido@ufrgs.br 